\title{
Gamer Girls: Navigating a Subculture of Gender Inequality
}

Robert L. Harrison

Jenna M. Drenten

Loyola University Chicago, jdrenten@luc.edu

Nicholas Pendarvis

Follow this and additional works at: https://ecommons.luc.edu/business_facpubs

Part of the Business Commons, and the Gender, Race, Sexuality, and Ethnicity in Communication Commons

Author Manuscript

This is a pre-publication author manuscript of the final, published article.

\section{Recommended Citation}

Harrison, Robert L.; Drenten, Jenna M.; and Pendarvis, Nicholas. Gamer Girls: Navigating a Subculture of Gender Inequality. Research in Consumer Behavior: Consumer Culture Theory, 18, : 47-64, 2016. Retrieved from Loyola eCommons, School of Business: Faculty Publications and Other Works,

This Article is brought to you for free and open access by the Faculty Publications and Other Works by Department at Loyola eCommons. It has been accepted for inclusion in School of Business: Faculty Publications and Other Works by an authorized administrator of Loyola eCommons. For more information, please contact ecommons@luc.edu. c) (†) $\ominus$

This work is licensed under a Creative Commons Attribution-Noncommercial-No Derivative Works 3.0 License. (c) Emerald Publishing 2016 
Harrison, Robert, Jenna Drenten, and Nicholas Pendarvis (2016), "Gamer Girls: Navigating a Subculture of Gender Inequality," in Russell W. Belk, Diego Rinallo, and Nil Özçaglar-Toulouse (Eds.), Research in Consumer Behavior: Consumer Culture Theory, Vol. 18, Bingley, UK: Emerald Group Publishing Limited, 47-64.

Note: This is a preprint version. The final published version of the paper may reflect notable format and content changes.

\title{
GAMER GIRLS: NAVIGATING A SUBCULTURE OF GENDER INEQUALITY
}

\begin{abstract}
Purpose - Video gaming, which remains culturally embedded in masculine ideals, is increasingly becoming a leisure activity for female consumers. Guided by social dominance theory, this chapter examines how female gamers navigate the masculineoriented gaming consumption context.

Methodology/Approach—Eight avid female gamers (ages 20-29) participated in depth interviews, following a phenomenological approach to better understand their lived experiences with video gaming. Data were analyzed using phenomenological procedures.

Findings - Findings reveal an undercurrent of gender-based consumer vulnerability, driven by stereotypical perceptions of "gamer girls" in the masculine-oriented gaming subculture. Further, the findings highlight the multilayered, multidimensional nature of gaming as a vulnerable consumption environment, at individual, marketplace, and cultural levels.

Social Implications - The culturally embedded gamer girl stereotype provides a foundation upon which characteristics of consumer vulnerability flourish, including a culture of gender-based consumer harassment, systematic disempowerment in the marketplace, and conflicting actions and attitudes toward future cultural change. Originality/Value - This research suggests female gamers struggle to gain a foothold in gaming due to the socially and culturally constructed masculine dominance of the field. Our research study provides a stepping-stone for future scholars to explore gendered subcultures and begins to address the dynamic interplay of power, gender, technology, and the market.
\end{abstract}

KEYWORDS: gender, consumer vulnerability, gaming, gamer girls, social dominance theory 


\section{INTRODUCTION}

In 2014, an Internet culture war ensued called \#Gamergate, in which a motley alliance of anti-feminist video gamers began harassing, criticizing, and threatening feminist gaming advocates who argued for greater positive representation of women in the video gaming industry (Parkin, 2014; Schroeder \& Borgerson, 2015). In one of the more disturbing incidents, an anonymous e-mailer threatened to bomb the Game Developers Choice Awards unless the organization rescinded an award it was presenting to feminist advocate Anita Sarkeesian, a key target in the \#Gamergate attacks (Wingfield, 2014). Despite the recent surge in public threats, harassment, and sexism against women in the gaming community, females represent a growing gamer demographic in the $\$ 15.4$ billion video gaming industry. Females represent $44 \%$ of U.S. video gamers, with females over 18 years of age representing the fastest growing consumer group, according to the Entertainment Software Association (2015). Yet, both men and women believe playing video games is a "particularly masculine pursuit" (Selwyn, 2007, p. 533). In a consumption context largely categorized as a "man's world", our research aims to understand how female video gamers experience, navigate, and cope with the male-dominated culture. Existing video game research concerning females addresses the representations of women in video games, portrayals women in gaming magazines, and female gamers' levels of play (Beasley \& Standley, 2002; Dill \& Thrill, 2007; Downs \& Smith, 2009; Kinder, 1991; Provenzo, 1991). As Jenson and de Castell (2010) conclude in their review of gaming and gender research, few studies explore "the masculine culture of digital gaming, commerce, commercialization, and media specifically" (p. 63). To that end, our research contributes to the literature by understanding how female gamers navigate the gaming consumption context, despite being systematically marginalized on a basis of gender alone. In addition, much of the existing literature is published outside of the marketing domain and focuses less on consumption experience and more on issues such as technological interface (see Royse, et al., 2007). Thus, our research aims to update the conversation about female consumers of video games, focusing specifically on marketing and consumption issues as lived experiences.

First, we introduce our theoretical foundation for the paper, reviewing literature on consumer vulnerability and gender, in relation to the gaming industry. Next, we outline our methodological approach, namely, phenomological depth interviews with eight avid female video gamers. Findings from our interviews reveal how stereotypical perceptions of "gamer girls" in the masculine-oriented gaming subculture breeds characteristics of consumer vulnerability, including a strong prevalence of genderbased consumer harassment, systematic disempowerment in the marketplace, and a 
defeatist attitude toward future cultural change. Lastly, we discuss the implications of our findings as they reveal a multifaceted view of consumer vulnerability in a gendered subculture of consumption.

\section{THEORETICAL FOUNDATION}

Previous research suggests video games reinforce hypermasculine stereotypes (Dill \& Thill, 2007) and sexism (Cassell \& Jenkins, 1998; Jenkins \& Cassell, 2008). Within video games, depictions of women are highly sexualized, both in image and in actions (Bryce \& Rutter, 2003; Williams, Martins, Consalvo, \& Ivory, 2009). As Kennedy (2002) suggests, female video game characters provide a "visual spectacle" for the masculine gaze. Likewise, the gaming industry itself reflects a male-dominated, often hostile work environment for female employees (Jenson \& de Castell, 2010; Kerr, 2003). While the percentage of male gamers surpasses female gamers, previous research suggests the two genders are in fact, quite similar in their motivations for playing. As Taylor (2012) notes, women are "all too frequently marginalized" thanks in part to "an imagined difference between men and women and gamers [which] remains a persistent myth" (p. 119). For instance, based on continuing longitudinal surveyresearch of massive multiplayer online games, Yee (2008) concludes, "the reality is that those men and women who currently play online games are overwhelmingly similar in terms of what they like to do with them. And stereotypical assumptions of gender motivations are either nonsignificant ... or are dwarfed by differences in age" (p. 9495). Despite the similarities between male and female gamers, the stereotype of video gaming as a masculine pursuit persists in the marketplace (Salter \& Blodgett, 2012). Thus, the purpose of this research is not to demonstrate differences between two genders (i.e., male vs. female); rather, we aim to understand female gamers' experiences in navigating the male dominated gaming market environment and the strategies they use to navigate threats to their consumption experience.

Previous consumer culture research establishes gender as a key factor of marginalization within the marketplace (Coleman, 2012). In particular, women have historically been perceived as the weaker and thus more marginalized gender in the marketplace (Bordo, 1993; Kilbourne, 1999). Feminist scholars suggest women are stereotypically and systematically exploited in the marketplace through advertising imagery (Gill, 2008), media representations (Gill, 2011), and economic inequity (Kuiper \& Sap, 1995), even from a very young age (Lamb and Brown, 2006). In the modern marketplace, the interaction between gender and the market is complex and dynamic (Schroeder, 2003; Scott, 2005). However, a tradition of gender-biased discourses is deeply rooted in the market, both among practitioners and scholars (Coleman, 2012). Women are positioned as the weaker gender, not because they are, but because 
cultural forces have constructed this perception to be the accepted truth. Scholars have recently begun to examine gender through a lens of consumer vulnerability, or "a state of powerlessness that arises from an imbalance in marketplace interactions" (Baker, Gentry, and Rittenburg, 2005, p. 134; Coleman, 2012). The power imbalance that creates the environment of vulnerability is linked to the binaries of male domination and female subordination. For instance, previous research on video gaming and gender remains centered on comparing men and women's preferences, abilities, and interest in gaming (Jenkins \& Cassell, 2008; Jenson \& de Castell, 2010). However, our approach goes beyond the male versus female gender dichotomy of sex-based stereotypes and considers instead, a marketplace context (e.g., video gaming), which is, itself, gendered (e.g., masculine).

To explore the experiences of female gamers through a perspective of consumer vulnerability, we ground our analysis broadly in social dominance theory, which explains the origin and consequence of social hierarchies and oppression (Sidanius \& Pratto, 1999). Social dominance theory assumes that we must understand the processes that maintain and produce discrimination at multiple levels of analysis, including cultural ideologies, institutional practices, and relations of individuals (Pratto, Sidanuis, \& Levin, 2006). This theory takes a systems approach to understanding how processes at different levels work together to produce systemic effects (Pratto, Sidanuis, \& Levin, 2006). In our investigation we take a similar approach to understand how multiple processes, at different levels, work together to create a system, or potentially vulnerable consumption environment for female gamers.

\section{METHOD}

Our research employs a phenomenological approach that focuses on lived experience, as opposed to "objective" descriptions, which often denotes an attempt to describe an event detached from its contextual environment (Pollio, 1982). Thompson, Locander, and Pollio (1989) describe this alternative perception of human experience as "...subscribing to a contextualist worldview (p. 135). Existentialphenomenologists do not wish to study individuals separate from the environments in which they live or the interaction of the two (which implies separation); rather, the study is of the totality of human-being-in-world." In this study, eight female gamers between the ages of 20-29 were interviewed to better understand their lived experiences with video gaming. We define a "female gamer" as a female individual who views and plays video games as an avid as opposed to casual leisure activity. The average length of each interview was between 60 and 75 minutes. Interviews were audiotaped and transcribed verbatim. The interviews began with broad grand tour questions, before continuing with questions related to their video game experiences. 
All informants were assured of individual confidentiality and pseudonyms are used for all participants in this study (see Table 1).

Table 1. Informant Profiles.

\begin{tabular}{ccl} 
PSUEDONYM & AGE & \multicolumn{1}{c}{ OCCUPATION } \\
\hline Tina & 20 & Video Game Store Employee \\
\hline Sara & 20 & College Student \\
\hline Alicia & 21 & College Student \\
\hline Bethany & 21 & College Student \\
\hline Kacey & 25 & Stay-at-home Mother \\
\hline Kerri & 25 & Video Game Store Employee \\
\hline Harriet & 28 & Stay-at-home Mother \\
\hline Corrine & 29 & Video Game Store Manager \\
\hline
\end{tabular}

Data analysis included the use of phenomenological procedures advanced by Colaizzi (1978), and as modified by Moustakas (1994). Our analysis is rooted in the tradition consumer culture theory, which conceptualizes culture as the very fabric of experience, meaning, and action (Arnould \& Thompson, 2005). Thus, we investigate how female gamers experience and make meaning from their interactions within a gendered consumption context.

\section{FINDINGS}

Our findings are organized around understanding experiences of gender inequality in the video game community. Gender inequality emerged as a permeating element of meaning and significant theme for our participants. We begin by describing the context, particularly how participants view "gamer girl" stereotypes associated with female gaming. We then discuss varying issues that contribute to the overall gendered cultural experience. Specifically, our findings indicate that the masculine-oriented gaming subculture is characterized by a strong prevalence of gender-based consumer harassment, systematic disempowerment in the marketplace, and a defeatist attitude toward future cultural change. These issues coalesce into a conversation about consumer vulnerability in this subculture of consumption (see Fig. 1. 
Fig.1. Female Gaming Model of Consumer Vulnerability.

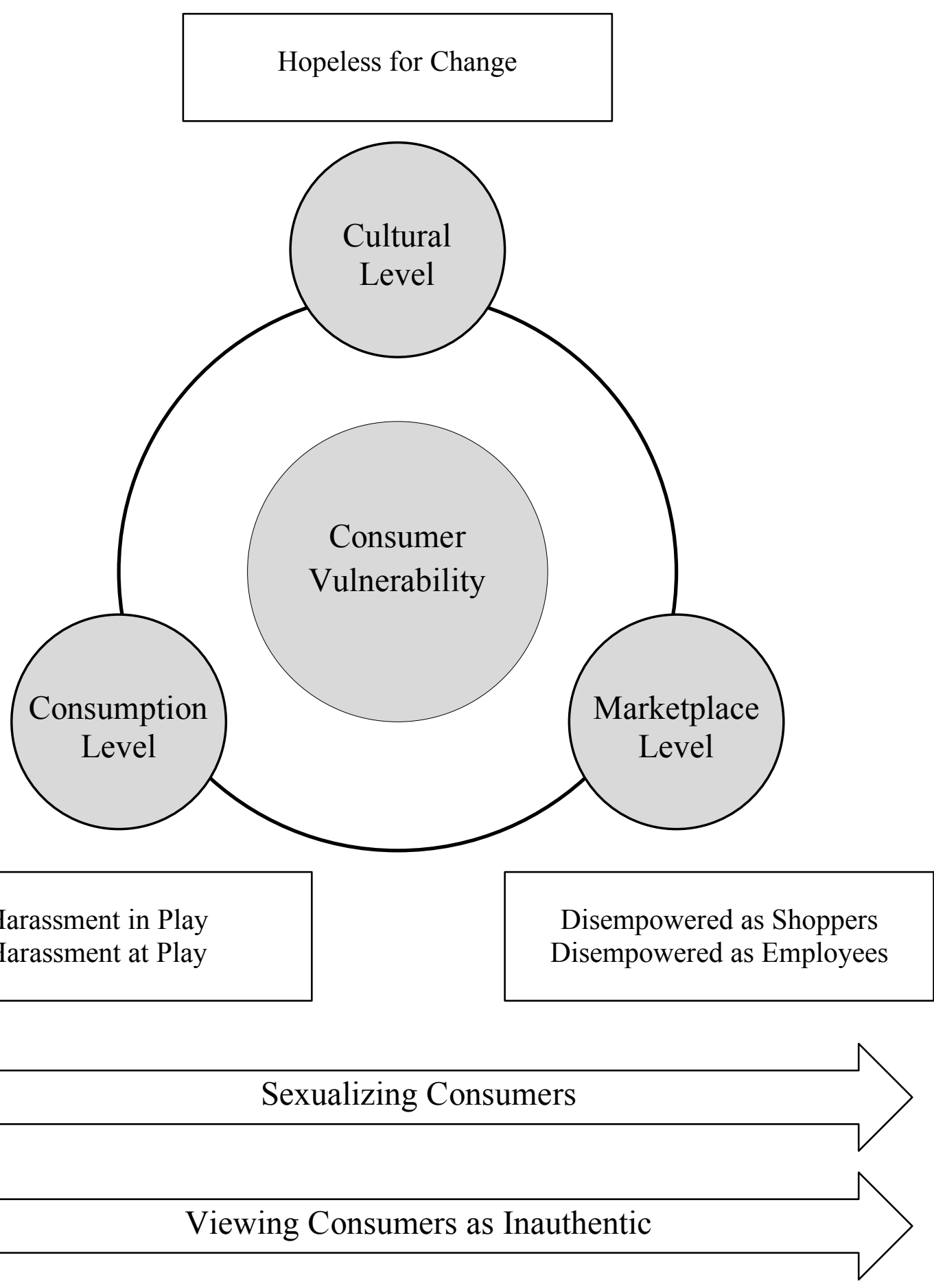




\section{What is a Gamer Girl?}

Females are motivated to play video gamers by feelings of achievement, power, and social interaction (Taylor, 2006). While research suggests women are more likely to play for the social interaction than men and view gaming as a way to interact with their significant offers (Williams, Consalvo, Caplan, \& Yee, 2009), the experiences of gamers trying to achieve such goals vary by gender. According to our participants, much of the variance is rooted culturally persistent "gamer girl" stereotypes. Namely, in the masculine-oriented gaming environment, gamer girls are highly sexualized and viewed as imposters by the gaming community. Across the data, the participants identify circumstances in which they had experienced sexism and systematic objectification.

I am just a gamer...[it's about] losing yourself, it is a passion. I started gaming when I was like two or three playing Mario, Mega Man, Castlevania. I am not posing for Playboy with a controller on my body. I do it because I like to do it and I am not doing it for any reason. I am not even doing it because I am a girl. I am doing it because I like the games. We all have our different motivations for playing the games: some like the graphics, some girls like the stories, some like the characters, some of us just like beating stuff with a stick. The stereotypes are that we are sexy, man-hunting women who can't get a man anywhere else, so we started gaming. Because apparently people think that female gamers are just there to hook up with these lovely luscious nerd men. (Kacey)

As the Kacey indicates, gamer girls play for a variety of reasons; however, the variations in their motives are not necessarily driven by gender. Nonetheless, she recognizes the prevailing sexy gamer girl stereotype within the gaming subculture. The data show a prevalence of sexism and objectification both on an interpersonal level and at a systematic industry level. For instance, Alexis notes that within the software itself, female gamers are given limited roles and options.

We call them boob physics. We always joke around that game developers have never seen real boobs because they can't, they don't bounce like that. They just don't work like that. And, then there's always the armor thing where female characters' armor's like: the higher level it gets, the more it becomes a bikini with magical powers. (Laughs) And guys' armor, they get this, like cool, you know, buff-cladden type stuff. And it's... it's always like, yeah, this one looks like they're going to a beach, and this one looks like they're actually going into war. (Alexis) 
The offline perception of a gamer girl as a sexualized object is perpetuated by the onscreen representation of female characters within the game. Female gamers recognize that the industry caters toward men and that the gaming subculture itself is a stereotypical male pursuit. Several participants referred to this as "fan servicing," in which game developers create highly sexualized feminine characters for the enjoyment of its masculine-dominant target market. Thus, the industry itself perpetuates antiquated perceptions of gender roles.

Of course [video games] are targeted towards men. It's a stereotype. Guys should playing video games. Girls should be cleaning. And guys should be good at sports and girls like to cook. But I mean, I don't like to cook, and I don't like to clean...you can see me just playing videos. I just feel like [the video game industry] should open up and have it geared towards girls and guys because guys aren't their only market. There are girls who play and actually enjoy games. (Sam)

As a gamer girl, Sam feels left out by the industry itself. Despite resisting traditional cultural categorizations of gender roles, she recognizes that men are the primary target market, and as a female, she is invisible. Across the data, participants note a variety of ways in which female gamers are edged out of the market based on pervasive gender stereotypes. These factors contribute to an overall perception of female gamers as inauthentic. For instance, Courtney notes, the term "gamer girl" itself demonstrates the gender rift that is pervasive in the gaming subculture.

Honestly, [gamer girl] is almost a negative connotation because-what, just because I am a female does not mean I am a gamer?-you know? I think gamers should just be gamers whether they are a guy or a girl. So you hear the term female gamer or gamer girl and it's almost, not really mocking necessarily, but kind of like we are not taken seriously. We have to be separated from real gamers. (Courtney)

As Courtney suggests, along with other participants, female gamers are overwhelmingly perceived as imposters or as inauthentic. Men are not called "gamer guys" as they are the default gender for the consumption community. As Sam noted previously, it is assumed that guys should be playing video games. In contract, female gamers must constantly prove themselves in the masculine gaming subculture in order to earn their status as gamers-not just gamer girls.

\section{Prevalence of Gender-based Consumer Harassment}

Our findings suggest that the pervasive "gamer girl" stereotypes contribute to an environment wherein female gamers are harassed, abused, and disrespected as 
consumers. By definition, these are representative experiences of consumer vulnerability, or a state of powerlessness that arises from an imbalance in marketplace interactions or from the consumption of products (Baker, Gentry, \& Rittenburg, 2005). Female gamer experiences are entrenched in traversing stereotypes and gender discrimination in order to achieve positive outcomes within the video game field. As such, consumer vulnerability emerged as integral to the overall meaning making process. Our findings uncover a prevalence of consumer harassment directed toward female gamers, who experience multi-faceted consumer vulnerability, both online and offline, within the gaming community.

Several respondents discussed negative experiences attributed to gendered harassment while gaming. Specifically, participants discussed verbal abuse in online chat communication and being hounded within games themselves, especially in MMOs (massively multiplayer online games). Sara and Alicia discussed their experiences of harassment.

When playing games like Halo and League of Legends they are notorious...you can talk to your teammates [online] and there is a high chance they are going to bash on you...telling me to go back to the kitchen, go have a baby, go get your nails done, or this isn't your place. It is the same insults over and over again, it gets old. And like... if you are playing League of Legends and you get points for fighting this monster or getting this item, well they find out you are a girl and they will go into the forest and kill the monster for you. They take $x$-rays from you, so when everyone is at max level $20 . .$. you are still at 14 and can't do shit. They keep you from being able to do anything and it makes the entire team lose because they are being dicks. They try to bar you from the goal because their entire goal is to make you lose just because there is a female on the game. (Sara)

A lot of times girls have to be extra careful about which games they go into and stuff, because like going into chatrooms and stuff, it can be a lot more difficult because you get a lot more harassments... a lot of times people use the derogatory terms towards females just because... they call me a bitch and stuff like that because am I was a female. If you're doing good, all of a sudden it's derogatory terms. And those are the times where just like disconnect immediately. And those are always the worst because you're like I didn't get to play this game I've been wanting to play, you know, I have to go for new community maybe, you know world or whatever, because this person's harassing me or whatever... but emotionally it's hard to hear that stuff all the time. And... it's... it, it 
causes safety concerns because it causes a lot of depression and issues and stuff for people that, that that are sensitive. \{she tears up\} (Alicia)

Other respondents discussed similar negative experiences of in-game harassment either through in-game interactions or online chat communication; but for Kacey negative experiences that she associated with gaming extended offline. My worst experience was playing World of Warcraft and I met a guy. We are talking and playing... I was thinking he seems nice, funny and there might be something, so I might as well meet him. It was a terrible experience, you hear about all the time online people being raped, it was one of those situations. He broke my phone, took advantage of me and left. So that was the worst experience ever, \{sigh; pause\} but it did not turn me off of gaming. (Kacey)

Here, Kacey is able to dissociate her negative offline experience with her positive view of online gaming. She clearly associates her assault, at least in part, to the experience of being a gamer girl, as she notes, her subsequent rape was her "worst experience ever" in conjunction with gaming. Nonetheless, she did not allow it to "turn her off" from the practice itself. The increasingly social and collaborative nature of online gaming produces an environment where women must find ways to manage, cope with, and at times avoid players with nefarious intentions. The data show that women are often overtly ridiculed, targeted, and denied access to valued ingame content. Access to valued game content and other such field-specific capital is important to gamers as it allows players to more readily perform game-related tasks as well as draw social distinctions among one another and accrue status within the community (Meades, 2013). By not being allowed to ascend the social hierarchy within their respective gaming communities these women experience feelings of powerlessness and are relegated to subordinate social roles. While many of these negative experiences are limited to online interactions women are also exposed to the potential for offline harassment.

Kacey and others suggest that another way to avoid the verbal and in-game harassment is by hiding their identity. Research suggests that gender swapping (or females playing as male characters and vice versa) in gaming is a form of play for male and females (Hussain \& Griffiths, 2008), but for female gamers it can also protect them from harassment. However, Kacey talked about how hiding ones identity was discussed as a double bind, as part of the allure of video gaming is to be identified as a winner. 
You want to represent yourself in the game, but you also feel like you have to keep yourself on the down-low, so you don't get told to go to the kitchen. (Kacey)

Kacey's statement reflects the delicate process of gaining status within the gaming community while actively avoiding ridicule from the deep-seated gender stereotypes embedded within the subculture. In line with Bourdieu (1980), making "one's own name" in the gaming field means making one's mark or achieving recognition of one's difference from others (p.289). This is central to obtaining cultural capital within the field and represents how female gamers can be restricted in these efforts. In sum, the impact of harassment is twofold. As a consequence of consumer harassment in online gaming women gamers often experience a sense of constrained social mobility and limited ability to fully participate within their respective communities. Additionally, these negative experiences also motivate women gamers impose self-limitations on the kinds of games they play as well as their level of social interaction within the community.

\section{Disempowerment in the Marketplace}

Our findings highlight how female gamers' negative gendered experiences extend to the off-line, retail environment, as participants discussed how not being viewed as authentic gamers makes purchasing video games unenjoyable. Corrine and Sara talked about assumptions made of female video game shoppers.

For us, going into a [video game store], everyone just assumes that you are there buying a game for a significant other. Going in as a shopper, a lot of time you are approached differently because you can't be there buying a game for yourself...right? I have heard the question "Do you play?" or "Are you buying this for yourself?" A guy comes in and it is just assumed with "What do you play?" Not "Do you play?" but "What do you play?" I don't think that they are realizing they are doing it, I don't think it's a purpose able thing but it's just an ingrained thing. It's a male thing. (Corrine)

I feel like girls are looked down upon, when I like would go buy a game, I would be embarrassed, like now I can do it, but back in the day, I would just be freaked out to go to buy a game by myself or like go into GameStop. I don't think I've ever been to GameStop by myself; it's just like awkward. I feel like when I'm in the gamer aisle, guys are like, oh man, look at her, she's buying a game...everyone just like glares at you...I used to have my dad buy my games for me, because he's a guy. (Sara) 
For Sara, Corrine, and others, the retail store environment is not an inviting one. The retail space for gaming is gendered, and female gamers develop coping strategies to merely shop for games-not just play them. For instance, as Sara mentions, she outsourced her gaming purchases to her father, for fear of discrimination-a key indicator of consumer vulnerability in the marketplace. Corrine, who manages a video game retail store, discussed work-experience issues related to being view as an inauthentic gamer girl.

Well, I have been a manager at [a video game retailer] for about five years now and quite often I get, "do you even play video games?" And I am just like "yes, I play video games, I work here so yeah." Or, they always want to talk to the boss, when it is obvious that I am training someone. They are talking to the guy that has been her for two days as opposed to me who has been here five years. I have answered the phone before and they ask if there is anyone there who has actually played video games that they can talk to. And I am always like "yeah me, because I play video games." I get a lot of that, on a daily basis. Whenever I hire a female, I always tell them that they have to have tough skin. You have to be prepared to be able to take whatever it is they are going to say to you and prove yourself. Whether you have to or shouldn't have to...you have to be ready to do that...can you handle this because it is going to come at you every day. (Corrine)

The excerpts above highlight how retail environments have the potential to produce negative social value for female consumer and employees. Social dominance theory suggests that members of dominant social groups tend to enjoy a disproportionate share of positive social value, or desirable symbolic resources and negative social value is disproportionately left to or forced upon members of subordinate groups such as stigmatization, and vilification (Pratto, Sidanuis, \& Levin, 2006). Moreover, the cautionary language used by Corrine when hiring a female employee to work in this male dominant field suggests that these women acknowledge their subjugated social positions in the gaming world and must be constantly prepared to respond to the negative interactions and unfair treatment. Gender-based subjugation appears to be perceived as a social norm in the community as these women must manage their expectations and deal with stigmatization. Corrine's warnings reflect a similar disempowerment discourse as found in Paul Henry's (2005) work on marketplace disempowerment. Henry (2005) describes consumers' experiences of empowerment and disempowerment as a function of selfperceptions that emerge from social class disparities and differential access to material 
and economic resources. The present work highlights how gender disparities creates a similar sentiment of disempowerment can emerge among women based on fieldspecific social capital in gaming culture as women in the gaming community often adopt the role and self-perception of "impotent reactors" who must constantly confront the potential for subjugation and "prove" themselves in the gaming community.

\section{Hopeless for Cultural Change}

Our participants talked about potential solutions to several issues related to negative consumer experiences. They suggested that change is needed the game industry level and that more female gamers are needed as developers and games creators. This would change how females are depicted in games. Much research exists on how females are either absent in games or exist to service male fantasies (Kennedy, 2002). However, at the community level, our participants are less hopeful that changes can be made to improve the environment for gamer girls. Kacey and Corrine discussed their pessimism.

Their hands are tied, they really are... because they want to get the players, they want to get the money, they want to have the events. If they try to get rid of everyone doing this [then] they might have less people buying their stuff. They don't want to lose their customers, they don't want to lose the male gamers or the female gamers. They have systems where you can report a player, and yes if they get reported so many times they get removed from the game and their computer code is band from playing the game. But with a quick reset of the computer, you can get back on...their hands are tied. (Corrine)

I don't know if you can. I think that is a people issue more than anything. They monitor it the best that they can, you can report people for calling people names, you can report people for aggressive or abusive behavior but I don't know if there is anything else that you can do. They are trying. They have this rating system I guess, I don't know exactly how it works but if you and I were playing with a bunch of people and someone starts spouting their mouth and being really negative than you can report that person. If that person gets enough reports they can get kicked off the system or get put into their only group of being jerks. (Kacey)

Corrine acknowledges the limitations and constraints placed on industry actors in attempting to make more of a direct appeal to women gamers while still meeting the demands of their core audience. The data suggests female gamers often feel that 
attempts to appeal to, or include women in more prominent or less sexualized roles may simultaneously discourage continued involvement by members of the community who have accepted the current gender-based norms. At the interpersonal level, Corrine also laments about the ineffectiveness of the current policies and selfreporting systems in place that are designed to protect gamers from exceedingly negative interactions. While she recognizes the potential for change in the community she remains doubtful that the actors and marketplace institutions with the power to bring about change are actually motivated to do so. Recent research in consumer culture views consumption communities as being constituted by an assemblage of consumers, producers and various forms of social, economic, and material resources (Thomas, Price \& Schau, 2013). It is the continuous interactions of actors at microsocial and institutional level that produce an active community. This perspective is reflected here in the way that female gamers view the actions of institutional actors, that tend to operate at a much broader social level, as having the potential impact the more microsocial experiences and interactions that they encounter daily in the community. What is emicly expressed in the preceding quote is that while female gamers are constantly finding new ways to manage and cope with negative experiences and inequality at the interpersonal level of the community they recognize that the potential for more inclusionary discourse and the broad reinforcement of gender equality within gaming culture lies at the institutional level.

\section{DISCUSSION}

Collectively, our research points toward a pervasive culture of gender-based consumer vulnerability in the gaming subculture. The findings highlight the multilayered, multidimensional nature of our vulnerable consumption environment, as our respondents experienced vulnerability at individual, marketplace, and cultural levels.

At the individual level, our findings represent a departure from existing consumer research by highlighting how consumers can experience discrimination and harassment in multiple dimensions during a consumption encounter; experiencing negative social value both "in play" through in-game harassment by way of goal obstruction and other prohibiting behaviors on the part of male gamers, and "at play" through verbal assaults in chatrooms while playing. In addition, the sexualization of female gamers is consistent with a second-wave feminist outlook, which frames the sexualization of female bodies as a mode of disempowerment (Bristor \& Fischer, 1993). It is this second wave outlook and the critical aspects of gender that often go missing in marketing scholarship (Maclaran, Miller, Parsons, \& Surman, 2009). 
At the marketplace level, existing research has highlighted how consumers experience discrimination in the shopping environment, usually related to racial experiences related to longing wait times (Ainscough \& Motley, 2000) and racial profiling (Crockett, Greir, \& Williams, 2003; Harris, Henderson, \& Williams, 2005). Gendered disempowerment is rarely explored as part of the shopping process, with the exception of the car buying process (Morton, Zettelmeyer, \& Silva-Risso, 2003). In addition, the gendered retail employee perspective offers added dimensionality to an understanding of vulnerable experiences in a consumption field; as cultural illegitimacy in the consumption field impacts marketplace experiences for female gamers retail shopping and employee experiences.

At the cultural level, female gamers experience a hopelessness associated with the prospect of evolutionary changes within the field. Social dominance theory holds that the dominant group or groups maintain their power in part by using various forms of oppression against less fortunate groups (e.g. Sidanius \& Pratto, 1999). In the work environment, it has been argued that women's progress constitutes a threat to the status quo of male dominance and female subordination and that the victimization of women can be explained as form of social control (Cortina, Lonsway, Magley, et al., 2002). The resistance at \#Gamergate appears to be mimicking this form control. The structural forces at the individual, group, and industry levels function to create feelings of hopeless that contributes to the vulnerable consumption environment and associated experiences.

The culturally embedded gamer girl stereotype provides a foundation upon which characteristics of consumer vulnerability flourish, including a culture of genderbased consumer harassment, systematic disempowerment in the marketplace, and conflicting actions and attitudes toward future cultural change. This research begins to explore the gaming subculture through the lens of social dominance theory, suggesting female gamers struggle to gain a foothold in gaming due to the socially and culturally constructed masculine dominance of the field. Female gamers engage in cultural reproduction of stereotypes while simultaneously coping with the practices of masculine dominance. This study provides a stepping-stone for future scholars to explore gendered subcultures and begins to address the dynamic interplay of power, gender, technology, and the market. 


\section{REFERENCES}

Ainscough, T. L., \& Motley, C. M. (2000). Will you help me please? The effects of race, gender and manner of dress on retail service. Marketing Letters, 11(2), 129-136.

Arnould, E. J., \& Thompson, C. J. (2005). Consumer Culture Theory (CCT): Twenty years of research. Journal of Consumer Research, 31(4), 868-882.

Baker, S. M., Gentry, J. W., \& Rittenburg, T. L. (2005). Building understanding of the domain of consumer vulnerability. Journal of Macromarketing, 25(2), 128-139.

Beasley, B., \& Collins Standley, T. (2002). Shirts vs. skins: Clothing as an indicator of gender role stereotyping in video games. Mass Communication \& Society, 5(3), 279-293.

Bordo, S. (1993). Feminism, Foucault and the politics of the body. In J. Price \& M. Shildrick (Eds.), Feminist Theory and the body: A reader. (pp. 246-57). New York, NY: Routledge.

Bourdieu, P. (1980). The production of belief: Contribution to an economy of symbolic goods. Media, Culture \& Society, 2, 261-293.

Bristor, J. M., \& Fischer, E. (1993). Feminist thought: Implications for consumer research. Journal of Consumer Research, 19(4), 518-536.

Bryce, J. O., \& Rutter, J. (2003). Gender dynamics and the social and spatial organization of computer gaming. Leisure Studies, 22(1), 1-15.

Cassell, J., \& Jenkins, H. (1998). From Barbie to Mortal Kombat: Gender and computer games. Cambridge, MA: MIT Press.

Colaizzi, P. (1978). Psychological research as the phenomenologist views it. In R. Valle \& M. King (Eds.), Existential-phenomenological alternatives for psychology, (pp. 48-71). Oxford, England: Oxford University Press.

Coleman, C. A. (2012). Construction of consumer vulnerability by gender and ethics of empowerment. In C.C. Otnes \& L. Tuncay Zayer (Eds.), Gender, culture, and consumer behavior, (pp. 3-32). New York, NY: Routledge.

Cortina, L. M., Lonsway, K. A., Magley, V. J., Freeman, L. V., Collinsworth, L. L., Hunter, M., \& Fitzgerald, L. F. (2002). What's gender got to do with it? Incivility in the federal courts. Law \& Social Inquiry, 27(2), 235-270.

Crockett, D., Grier, S. A., \& Williams, J. A. (2003). Coping with marketplace discrimination: An exploration of the experiences of black men. Academy of Marketing Science Review, 2003(4), 1-21.

Dill, K. E., \& Thill, K. P. (2007). Video game characters and the socialization of gender roles: Young people's perceptions mirror sexist media depictions. Sex roles, 57(11-12), 851-864.

Downs, E., \& Smith, S. L. (2010). Keeping abreast of hypersexuality: A video game character content analysis. Sex Roles, 62(11-12), 721-733. 
Entertainment Software Association. (2015). Entertainment Software Rating Board (ESRB). Retrieved November 30, 2015, from http://www.esrb.org.

Gill, R. (2008). Empowerment/sexism: Figuring female sexual agency in contemporary advertising. Feminism \& Psychology, 18(1), 35-60.

Gill, R. (2011). Supersexualize me! Advertising and the "midriffs." In G. Dine \& J. M. Humez (Eds.), Gender, race, and class in media: A text-reader, (Volume 3, pp. 255-260). Thousand Oaks, CA: SAGE Publications.

Harris, A. M. G., Henderson, G. R., \& Williams, J. D. (2005). Courting customers: Assessing consumer racial profiling and other marketplace discrimination. Journal of Public Policy \& Marketing, 24(1), 163-171.

Henry, P. C. (2005). Social class, market situation, and consumers' metaphors of (dis) empowerment. Journal of Consumer Research, 31(4), 766-778.

Hussain, Z., \& Griffiths, M. D. (2008). Gender swapping and socializing in cyberspace: An exploratory study. CyberPsychology \& Behavior, 11(1), 47-53.

Jenkins, H., \& Cassell, J. (2008). From Quake Grrls to Desperate Housewives: A decade of gender and computer games. In Y. Kafai, C. Heeter, J. Denner, \& J. Sun (Eds.) Beyond Barbie and Mortal Kombat: New perspectives on gender and gaming, (pp. 5-20). Cambridge, MA: MIT Press.

Jenson, J., \& de Castell, S. (2010). Gender, simulation, and gaming: Research review and redirections. Simulation \& Gaming, 41(1), 51-71.

Kennedy, H. W. (2002). Lara Croft: Feminist icon or cyberbimbo? On the limits of textual analysis. The International Journal of Computer Game Research, 2(2). Retrieved July 4, 2016, from http://www.gamestudies.org/0202/kennedy/.

Kerr, A. (2003). Girls/women just want to have fun-a study of adult female players of digital games. In DiGRA '03 - Proceedings of the 2003 DiGRA International Conference: Level Up, (Vol. 2, pp. 270-285). Utrecht, AN: University of Utrecht.

Kilbourne, J. (1999). Can't buy my love: How advertising changes the way we think and feel. New York, NY: Touchstone.

Kinder, M. (1991). Playing with power in movies, television, and video games: From Muppet Babies to Teenage Mutant Ninja Turtles. Berkeley, CA: University of California Press.

Kuiper, E., \& Sap, J. (1995). Out of the margin: Feminist perspectives on economics. New York, NY: Routledge.

Lamb, S., \& Brown, L. M. (2006). Packaging girlhood: Rescuing our daughters from marketers' schemes. New York, NY: St. Martin's Press.

Maclaran, P., Miller, C., Parsons, E., \& Surman, E. (2009). Praxis or performance: Does critical marketing have a gender blind-spot? Journal of Marketing Management, 25(7-8), 713-728. 
Meades, A. F. (2013). Infectious pleasures: Ethnographic perspectives on the production and use of illicit videogame modifications on the Call of Duty franchise. Journal of Gaming \& Virtual Worlds, 5(1), 59-76.

Morton, F. S., Zettelmeyer, F., \& Silva-Risso, J. (2003). Consumer information and discrimination: Does the internet affect the pricing of new cars to women and minorities? Quantitative Marketing and Economics, 1(1), 65-92.

Moustakas, C. (1994). Phenomenological research methods. Thousand Oaks, CA: SAGE Publications.

Parkin, S. (2014, October 17). Gamergate: A scandal erupts in the video-game community. The New Yorker. Retrieved from http://www.newyorker.com/tech/elements/gamergate-scandal-erupts-videogame-community.

Pollio, H. R. (1982). Behavior and existence: An introduction to empirical humanistic psychology. Monterey, CA: Brooks/Cole.

Pratto, F., Sidanius, J., \& Levin, S. (2006). Social dominance theory and the dynamics of intergroup relations: Taking stock and looking forward. European Review of Social Psychology, 17(1), 271-320.

Provenzo Jr, E. F. (1991). Video kids: Making sense of Nintendo. Cambridge, MA: Harvard University Press.

Royse, P., Lee, J., Undrahbuyan, B., Hopson, M., \& Consalvo, M. (2007). Women and games: Technologies of the gendered self. New Media \& Society, 9(4), 555-576.

Salter, A., \& Blodgett, B. (2012). Hypermasculinity \& dickwolves: The contentious role of women in the new gaming public. Journal of Broadcasting \& Electronic Media, 56(3), 401-416.

Schroeder, J. (2003). Guest editor's introduction: Consumption, gender and identity. Consumption Markets \& Culture, 6(1), 1-4.

Schroeder, J. E., \& Borgerson, J. L. (2015). Critical visual analysis of gender: Reactions and reflections. Journal of Marketing Management, 31(15-16), 1723-1731.

Scott, L. M. (2005). Fresh lipstick: Redressing fashion and feminism. New York, NY: Palgrave MacMillan.

Selwyn, N. (2007). Hi-tech = guy-tech? An exploration of undergraduate students' gendered perceptions of information and communication technologies. Sex Roles, 56(7-8), 525-536.

Sidanius, J., \& Pratto, F. (1999). Social dominance: An intergroup theory of social hierarchy and oppression. Cambridge, UK: Cambridge University Press.

Taylor, T. L. (2006). Playing between worlds: Exploring on-line game culture. Cambridge, MA: MIT Press.

Taylor, T. L. (2012). Raising the stakes: E-sports and the professionalization of computer gaming. Cambridge, MA: MIT Press. 
Thompson, C. J., Locander, W. B., \& Pollio, H. R. (1989). Putting consumer experience back into consumer research: The philosophy and method of existentialphenomenology. Journal of Consumer Research, 16(2), 133-146.

Thomas, T. C., Price, L. L., \& Schau, H. J. (2013). When differences unite: Resource dependence in heterogeneous consumption communities. Journal of Consumer Research, 39(5), 1010-1033.

Williams, D., Consalvo, M., Caplan, S., \& Yee, N. (2009). Looking for gender: Gender roles and behaviors among online gamers. Journal of Communication, 59(4), 700-725.

Williams, D., Martins, N., Consalvo, M., \& Ivory, J. D. (2009). The virtual census: Representations of gender, race and age in video games. New Media \& Society, 11(5), 815-834.

Wingfield, N. (2014, October 15). Feminist critics of video games facing threats in 'GamerGate' campaign. The New York Times. Retrieved from http://www.nytimes.com/2014/10/16/technology/gamergate-women-videogame-threats-anita-sarkeesian.html.

Yee, N. (2008). Maps of digital desires: Exploring the topography of gender and play in online games. In Y.B. Kafai, C. Heeter, J. Denner, \& J. Y. Sun (Eds.), Beyond Barbie and Mortal Kombat: New perspectives on gender and gaming, (pp. 8396). Cambridge, MA: MIT Press. 